\title{
Synthesis of Propyl-Sulfonic Acid-Functionalized Nanoparticles as Catalysts for Cellobiose Hydrolysis
}

\author{
L. Peña ${ }^{*}$, K. L. Hohn' ${ }^{2}$, J. Li ${ }^{3}$, X. S. Sun ${ }^{4}$, D. Wang1 \\ ${ }^{1}$ Department of Biological and Agricultural Engineering, Kansas State University, Manhattan, USA \\ ${ }^{2}$ Department of Chemical Engineering, Kansas State University, Manhattan, USA \\ ${ }^{3}$ Department of Chemistry, Kansas State University, Manhattan, USA \\ ${ }^{4}$ Department of Grain Science and Industry, Kansas State University, Manhattan, USA \\ Email: dwang@ksu.edu
}

Received 22 August 2014; revised 19 September 2014; accepted 23 October 2014

Copyright (C) 2014 by authors and Scientific Research Publishing Inc.

This work is licensed under the Creative Commons Attribution International License (CC BY).

http://creativecommons.org/licenses/by/4.0/

(c) (i) Open Access

\begin{abstract}
Functionalization of silica surfaces using organo-silanes is highly sensitive to reaction conditions. Silica-coated nanoparticles were functionalized with propyl-sulfonic acid groups (PS) under different synthesis conditions including, various solvents (Ethanol, methanol, acetonitrile, and toluene), water content in the reaction media $(0 \%$ to $50 \%), 3$-mercaptopropyl-trimethoxysilane concentration (MPTMS) $(0.5 \%$ to $10 \%)$, and reaction time (6 to $16 \mathrm{~h})$. Size of the PS-nanoparticles was determined by TEM and varied from 3.5 to $20.3 \mathrm{~nm}$ with sulfur load. Elemental analysis revealed sulfur contents from $0.8 \%$ to $22 \%$. FTIR analysis showed increased C-H band intensities with increasing sulfur content of PS-nanoparticles. Although PS-nanoparticles with sulfur loads under 3\% did not improve the hydrolysis of cellobiose, PS acid-functionalized nanoparticles with about $6 \% \mathrm{~S}$ achieved $96.0 \%$ cellobiose conversion. The control experiment, without catalyst, converted $32.8 \%$ of the initial cellobiose. PS-nanoparticles with $(6 \%-8 \% \mathrm{~S})$ were obtained using $(0.5 \%)$ silane concentration and 15 - $16 \mathrm{~h}$ reaction time in ethanol.
\end{abstract}

\section{Keywords}

Surface, Nanoparticles, Cellobiose, Hydrolysis

\section{Introduction}

One of the challenges in the production of renewable fuels and chemicals from lignocellulosic biomass is

*L. Pena's current address is Department of Agricultural and Biological Engineering, Pennsylvania State University, State College, USA.

How to cite this paper: Peña, L., Hohn, K.L., Li, J., Sun, X.S. and Wang, D. (2014) Synthesis of Propyl-Sulfonic Acid-Functionalized Nanoparticles as Catalysts for Cellobiose Hydrolysis. Journal of Biomaterials and Nanobiotechnology, 5, 241-253. http://dx.doi.org/10.4236/jbnb.2014.54028 
breaking down the complex structure of biomass into monomeric sugars. Biomass comprises a complex mixture of cellulose, hemicellulose, and lignin [1]. Cellulose is a polymer of glucose units linked by $\beta$-1,4-glycosidic linkages. Cellobiose, a disaccharide of glucose, is the true repeating unit of the cellulose polymer [2]. The $\beta-1,4$ bonds between glucose units allow the formation of hydrogen bonds between adjacent chains and make the structure of the polymer highly stable and resistant to hydrolysis [3]-[5]. Currently, the most accepted process for production of cellulosic ethanol uses an acid hydrolysis to pretreat lignocellulosic biomass and an enzymatic hydrolysis to break the cellulose chains into monomer sugars [6]. Cellulolytic enzymes are a big portion of the operational cost to produce cellulosic ethanol because they are expensive catalysts with limited reusability [7] [8]. These enzymes work optimally under a narrow set of conditions, plus reaction rates are slow [9] [10]. The efficiency of enzymatic hydrolysis of cellulose affects the economic feasibility of the process. Solid catalysts could act similarly to cellulolytic enzymes, with the additional benefits that these catalysts can be recovered and reused and could work well under a broad set of conditions [11]-[14]. Although a number of articles have been published on the performance of heterogeneous catalysts on the hydrolysis of glycosidic bonds [15]-[18], research is in the early stage and more investigation is needed.

Organosilanes are broadly used for modification of surfaces to produce materials with special properties. Condensation of an organosilane on a surface gives the surface new attributes depending on its functional groups. Extensive literature is available on the modification of siliceous materials. This technology has been utilized in numerous coating applications on glass surfaces [19]-[22]. Alkyl-silanes are attractive silica coupling agents because of the high stability of the Si-C bond. Silanating agents such as 3-mercaptopropyl-trimethoxysilane (MPTMS) have three leaving groups, and this feature gives the molecule the chance to anchor through more than one silanol group on siliceous surfaces [23].

One specific application of silica surface modification is to produce catalytic materials. The attachment of a catalytic group on a solid surface allows its recovery and reutilization. The catalytic groups are usually placed on porous materials because these materials can hold a larger number of the functional moieties. Propyl-sulfonic acid-functionalized silicas have been used on acid catalysis in several studies [24] [25]. Nevertheless, using heterogeneous catalysis brings about mass transfer issues that could decrease the efficiency of the catalysis. Nanocatalysts are a hybrid of heterogeneous and homogeneous catalysts. Functionalized nanoparticles can be used for catalysis of liquid and gas-phase reactions and can be separated and recovered from the reaction media [26]-[28]. At the same time, nanocatalysts have properties similar to those of homogeneous catalysts because they are very small and can be accessed easily by the reactants, circumventing the diffusion problems that solid catalysts could present. Similar to silica surfaces, the surface of nanoparticles can be modified to confer them with desired chemical features [29].

Numerous studies have been reported on functionalization of nanoparticles for various applications [28] [30]-[32]. In previous work, for instance, magnetic nanoparticles have been successfully coated with silica [33] [34]. These nanoparticles can be separated out of aqueous solutions using a magnetic field, and their silica surface can be further modified. The functionalization of silica-coated nanoparticles can be done using procedures similar to those reported on acid functionalization of silicas [34] [35]. Silica-coated nanoparticles could be treated in the same manner as siliceous materials because these nanoparticles have silanol groups sticking out from their surfaces. Although extensive work has been published in the area of coating with organosilanes, the production of a good film is a complex and delicate process. In aqueous solutions, the functionalization of silica with MPTMS occurs through a two-step reaction [36]-[39]. In the first step, the silane is hydrolyzed into hydrolyzate or alkyl-silanol, releasing three molecules of methanol (Figure 1, step 1). In the second step, the organosilanol condenses on the surface through the formation of silicon-oxygen bonds with the hydroxyl groups of the surface (Figure 1, step 2). Neighboring silanol groups ( $\mathrm{Si}-\mathrm{OH}$ ) can crosslink and release water; this stabilizes the coating and prevent their detachment from the surface [38]. Then, the mercapto-propyl groups are oxidized to sulfonic acid groups using a hydrogen peroxide solution (Figure 1, step 3). Silanol solutions are unstable in the presence of water. Before they are linked to the surface, silanol molecules can condense with each other and then the solution hazes [40] (Figure 1, step 4). Stability of silane solutions can be determined by measuring the time it takes for the solution to haze to the point that a printed page cannot be read through a clear bottle [39]. Another mechanism by which the modification could occur is through the condensation of siloxanols upon the surface [36]. This physisorbed layer would be attached to the surface by weak linkages such as hydrogen bonds or van der Waals forces; it could be easily washed off by the solvent or hydrolyzed by water [36] [41].

The loading of functional groups on silica surfaces is greatly influenced by the presence of water, solvent polarity, silane concentration, and reaction time [39] [42]. Glass et al. summarized a number of protocol parame- 


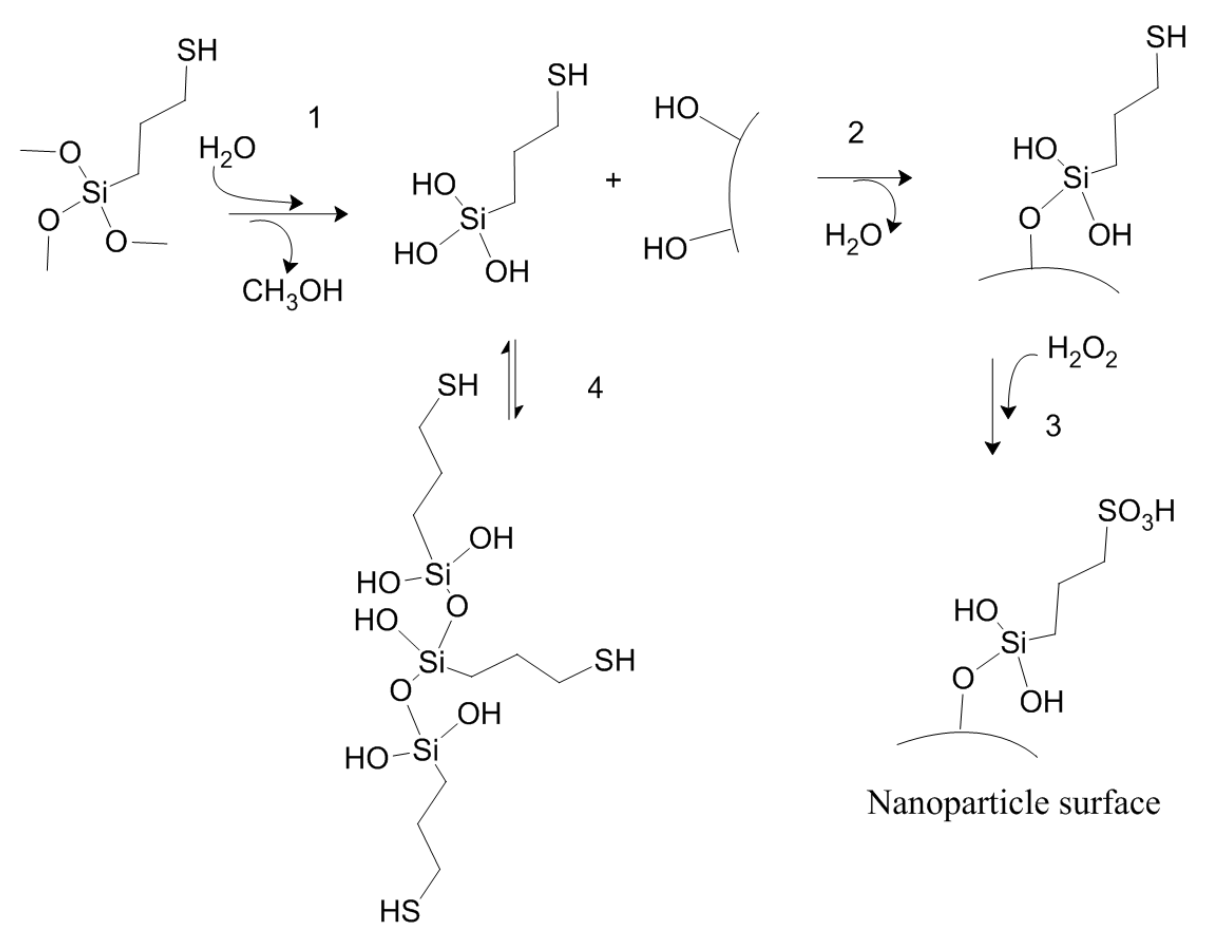

Figure 1. Schematic of the preparation of propyl-sulfonic acid-functionalized nanoparticles.

ters for organosilane deposition. Among others, the solvents used in these protocols were toluene, ethanol, isopropanol, acetone, and benzene. The reaction time varied from seconds up to $24 \mathrm{~h}$, and the silane concentration varied from 0.1 up to 50\% [19]. Such parameters are also expected to affect the number of acid sites placed on silica-coated nanoparticles. In this work, various synthesis conditions were used to functionalize silica-coated cobalt iron oxide nanoparticles with propyl-sulfonic acid groups. The objective of this research was to investigate the effect of synthesis conditions on the loading of organosilane on the nanoparticle surface and evaluate the performance of the functionalized nanoparticles for the hydrolysis of cellobiose into glucose. A schematic representation of the cellobiose hydrolysis using PS-nanoparticles is shown in Figure 2.

\section{Methods and Materials}

\subsection{Materials}

Cobalt (II) chloride hexahydrate (99\%), D-(+)-Cellobiose (98\%), iron (II) chloride tetrahydrate (99.99\%), 3mercaptopropyltrimethoxysilane (MPTMS) (95\%), methylamine (40\%w/w, 98.5\%), sodium dodecyl sulfate (98.5\%), and tetraethylorthosilicate (TEOS) (99.999\%) were purchased from Sigma-Aldrich (St. Louis, MO). Acetonitrile, ammonium hydroxide, hydrogen peroxide, isopropanol, methanol, and toluene (A.C.S. reagent) were purchased from Fisher Scientific (Pittsburgh, PA). Ethanol (95\%) was purchased from Decon Laboratories (King of Prussia, PA).

\subsection{Synthesis of $\mathrm{CoFe}_{2} \mathrm{O}_{4}$}

Cobalt iron oxide $\left(\mathrm{CoFe}_{2} \mathrm{O}_{4}\right)$ was synthesized by precipitating salts of $\mathrm{Co}^{+2}$ and $\mathrm{Fe}^{+2}$ using a microemulsion method [43] [44]. In a typical experiment, a solution was prepared with 4 mmol ( 0.9 g) of cobalt (II) chloride hexahydrate $\mathrm{CoCl}_{2} \cdot 6 \mathrm{H}_{2} \mathrm{O}, 10 \mathrm{mmol}\left(1.9 \mathrm{~g}\right.$ ) of iron (II) tetrahydrate $\mathrm{FeCl}_{2} \cdot 4 \mathrm{H}_{2} \mathrm{O}$, and $45 \mathrm{mmol}$ (12.9 g) of sodium dodecyl sulfate (SDS). The salts and surfactant were dissolved in distilled water, mixed, and diluted to $1 \mathrm{~L}$. One liter solution of $12 \mathrm{wt} \%$ methylamine was also prepared. After stirring the first solution for $30 \mathrm{~min}$ at room temperature, both solutions were heated to $55^{\circ} \mathrm{C}-65^{\circ} \mathrm{C}$ and then combined. The mixture was kept at $55^{\circ} \mathrm{C}-65^{\circ} \mathrm{C}$ under rigorous mechanical stirring. After $3 \mathrm{~h}$, the particles were magnetically separated and washed three times with water and once with ethanol, then stored in $100 \mathrm{~mL}$ of ethanol. 


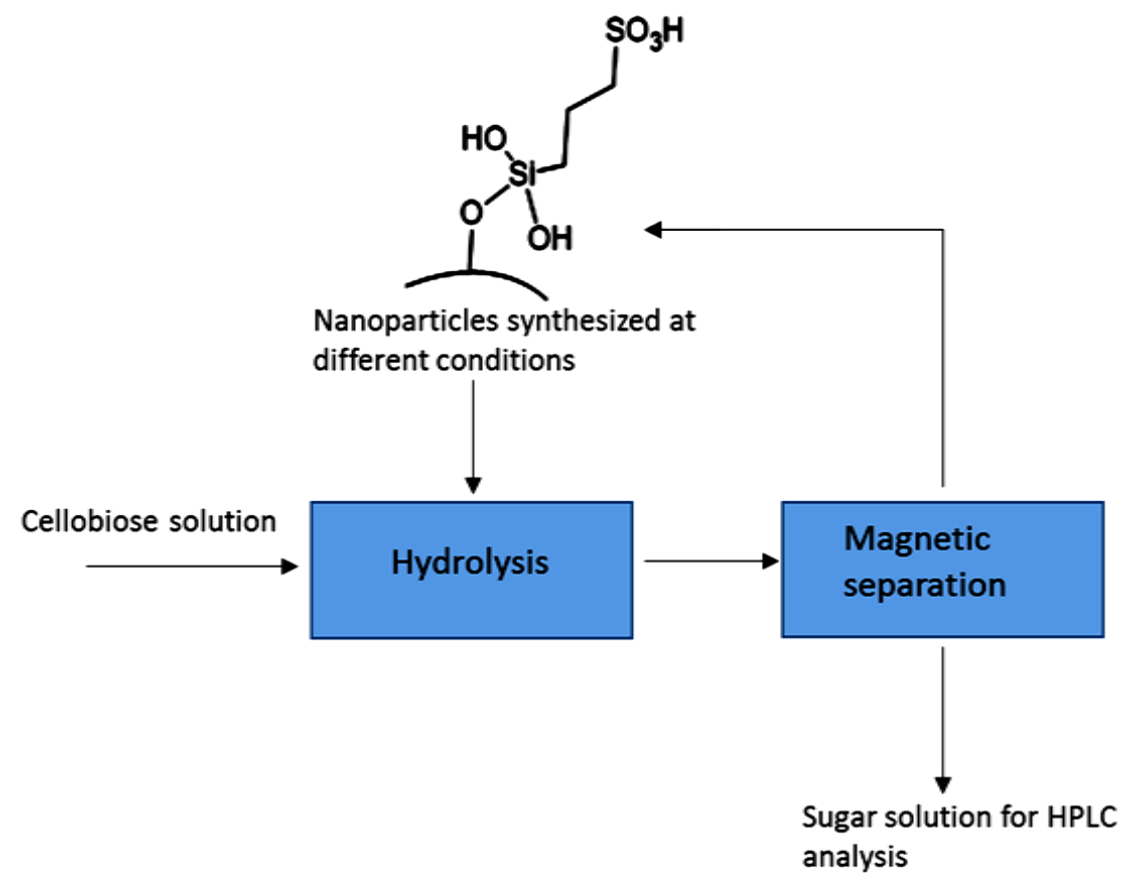

Figure 2. Schematic representation of cellobiose hydrolysis catalyzed with PS-nanoparticles.

\subsection{Silica Coating of $\mathrm{CoFe}_{2} \mathrm{O}_{4}$}

Cobalt iron oxide nanoparticles were coated with silica using the procedures reported in the literature [34]-[46]. The dispersion of $\mathrm{CoFe}_{2} \mathrm{O}_{4}$ in ethanol was sonicated for $1 \mathrm{~h}$. Then about $15 \mathrm{ml}$ of this solution were added to $550 \mathrm{ml}$ of a mixture of isopropanol and water in a 9:1 ratio. This solution was sonicated and mechanically stirred for $30 \mathrm{~min}$. One $\mathrm{mL}$ of tetraethylorthosilicate (TEOS) was diluted in $40 \mathrm{~mL}$ of isopropanol. After the 30-min stirring period, $50 \mathrm{~mL}$ of concentrated ammonium hydroxide were added, and the dilute TEOS solution was added dropwise at a rate of $0.3 \mathrm{ml} / \mathrm{min}$. After the addition of the TEOS solution, the mixture was sonicated for another hour. Then the silica-coated magnetic nanoparticles (SiMNPs) were magnetically separated, washed four to five times with water, and dried at $105^{\circ} \mathrm{C}$ in a forced-air convection oven.

\subsection{Functionalization of Silica-Coated Magnetic Nanoparticles (SiMNPs)}

Silanol groups in silica surfaces react with silane coupling agents by dehydration [47]-[49] or hydrolysis of the silane in the presence of water [34]. Solvent polarity, MPTMS concentration, and time affect the synthesis of mercaptopropyl-functionalized nanoparticles, and subsequently the loading of the sulfonic acid-functional group on propyl-sulfonic (PS) acid-functionalized nanoparticles [42]. PS nanoparticles were synthesized with the synthesis conditions shown in Table 1. In a typical experiment, $500 \mathrm{mg}$ of dry SiMNPs were sonicated in the solvent for $1 \mathrm{~h}$. After sonication, MPTMS was added, and the blend was refluxed and mechanically stirred. After the reaction, the nanoparticles were allowed to cool and then were magnetically separated from the reaction media. The mercaptopropyl-functionalized nanoparticles were washed three times with ethanol, isopropanol, or hexane according to the solvent used for the reaction. Then, the nanoparticles were placed in $60 \mathrm{ml}$ solution with equal amounts of water, methanol, and hydrogen peroxide for oxidization of the mercapto groups. After $48 \mathrm{~h}$ in this solution, the nanoparticles were washed three times with distilled water and left overnight in $10 \mathrm{~mL}$ of 0.1 $\mathrm{M}$ sulfuric acid. The solution was then washed multiple times with distilled water until the $\mathrm{pH}$ remained constant. Then, the samples were dried at $105^{\circ} \mathrm{C}$ for $24 \mathrm{~h}$.

\subsection{Characterization of PS-Nanoparticles}

The transmission electron microscope (TEM) images were used to estimate the size and size distribution of the nanoparticles. A TEM (model CM100, FEI Company, Hillsboro, OR) equipped with an AMT digital image 
Table 1. Synthesis conditions to obtain acid-functionalized nanoparticles.

\begin{tabular}{cc}
\hline Parameter & Typical Values \\
\hline Water Content (\%) & $0,2,10,30,50$ \\
MPTMS Concentration (\%) & $0.5,1,2,4,5,10$ \\
Solvent & Ethanol, Methanol, Acetonitrile, Toluene \\
Time (h) & $6,8,10,15,16$ \\
\hline
\end{tabular}

capturing system was operated at $100 \mathrm{kV}$. The nanoparticles were placed onto Formvar/carbon-coated, 200mesh copper grids (Electron Microscopy Sciences, Fort Washington, PA), then viewed by TEM. The size distribution of the nanoparticles was calculated using ImageJ software from the National Institutes of Health.

Fourier transform infrared (FTIR) spectra were used to confirm the presence of the propyl-sulfonic acid bonds in the synthesized nanoparticles. The spectra and peak positions were determined using an infrared spectrometer and its spectrum software (Spectrum 400, PerkinElmer Inc., Waltham, MA). The measurement was carried out in the wave number range $500-4000 \mathrm{~cm}^{-1}$, with $4 \mathrm{~cm}^{-1}$ resolution and 32 scans per sample.

Hydronium ion concentration per unit mass of catalyst was determined with an ion-exchange titration method [48] [50]. To withdraw the hydronium ions from the catalyst, $0.05 \mathrm{~g}$ of catalyst was added to $20 \mathrm{ml}$ of sodium chloride ( $\mathrm{NaCl}, 2 \mathrm{mM}$ ). The nanoparticle suspensions were homogenized, sonicated, and left overnight at room temperature. After $24 \mathrm{~h}$, the particles were separated from the solution using centrifugation. The particles were re-dispersed in another $20 \mathrm{ml}$ of sodium chloride, and the previous salt solution was set aside. Again the particles were homogenized, sonicated, and left overnight. Then, the particles were separated from the solution. Finally, the salt solutions were titrated to neutrality with a $0.01 \mathrm{M} \mathrm{NaOH}$ solution. Samples were analyzed after each synthesis batch in duplicate.

Sulfur content was used as an indicator of the silane grafting level on the nanoparticles, and it was determined by an elemental analyzer (Model 2400 Series II, PerkinElmer Inc.). The percentage of sulfur involved in sulfonic acid groups was calculated from the ion exchange capacity values by multiplying the milimoles of hydronium ions by the atomic mass of sulfur. The percentage of sulfur involved in mercap to groups $\left(\% \mathrm{~S}_{\mathrm{SH}}\right)$ was calculated by subtracting the percentage of sulfur from sulfonic acid groups $\left(\% \mathrm{~S}_{- \text {-озн }}\right)$ to the total sulfur content measured through chemical analysis $\left(\% \mathrm{~S}_{\text {total }}\right)$.

\subsection{Hydrolysis of Cellobiose}

The catalytic ability of the PS nanoparticles to hydrolyze the $\beta-1-4$ glycosidic bond was evaluated using $4 \mathrm{mg} / \mathrm{ml}$ cellobiose solutions with $1 \%(\mathrm{w} / \mathrm{w})$ PS nanoparticles. The dispersions were sonicated for $20 \mathrm{~min}$, then placed in a 60-ml Swagelok tube reactor (Swagelok, Kansas City Valve \& Fitting Co., KS) made from 316-L stainless steel with a measured internal volume of $75 \mathrm{~mL}$ (outside diameter of $38.1 \mathrm{~mm}$, length of $125 \mathrm{~mm}$, and wall thickness of $2.4 \mathrm{~mm}$ ) [51] [52]. The reaction was carried out at $175^{\circ} \mathrm{C}$ for $30 \mathrm{~min}$ in a sand bath (Techne, Inc., Princeton, NJ). Two replicates were run for all experiments. The control experiment was carried out under the same conditions as the experiments using PS nanoparticles. The control experiment had no catalyst and was referred to as hydro-thermolysis. After the reaction, the solutions were analyzed by HPLC to determine the glucoseyield and residue cell obiose using a RCM-Ca ${ }^{+2}$ monosaccharide column $(300 \times 7.8 \mathrm{~mm}$; Phenomenex, Torrance, CA) and refractive index detector. Samples were run at $80^{\circ} \mathrm{C}$ at $0.6 \mathrm{ml} / \mathrm{min}$ with water as mobile phase [53]. To calculate the glucose yield, the moles of glucose in the solution were divided by the theoretical amount of glucose that could have been obtained from cellobiose.

\section{Results and Discussion}

The acid loading in PS nanoparticles varied from 0.02 - $0.59 \mathrm{mmol} \mathrm{H}^{+} / \mathrm{g}$ among all solvents used (Table 2). The range of the acid loading values from this research agrees with values previously reported for propyl-sulfonic acid-functionalized silicas [54]; however, the acid capacity of some of the nanoparticles was probably underestimated because the nanoparticles could not be dispersed in the $\mathrm{NaCl}$ solution. Nanoparticles that gained a high load of propyl groups floated on the top of the solution and were difficult to disperse in aqueous solutions, so not 
Table 2. Sulfur analysis and ion exchange titration results by solvent used during grafting.

\begin{tabular}{cccc}
\hline & oS $_{\text {total }}{ }^{\mathrm{a}}$ & $\mathrm{mmol} \mathrm{H}^{+} / \mathrm{g}$ & \% $_{- \text {SOЗ3H }^{\mathrm{b}}}$ \\
\hline Toluene & 0.77 & 0.05 & 0.16 \\
Acetonitrile & 0.26 & 0.02 & 0.05 \\
Ethanol & 0.41 & 0.08 & 0.26 \\
Methanol & 3.15 & 0.07 & 0.21 \\
Ethanol/Water & 18.59 & 0.59 & 1.88 \\
\hline
\end{tabular}

${ }^{a}$ Mass percentage of $\mathrm{S}$ atoms over total mass of nanoparticlesdetermined from elemental analysis. ${ }^{\mathrm{b}}$ Sulfur percentage involved in sulfonic acid groups; calculated as 3.2 times themmol $\mathrm{H}^{+} / \mathrm{g}$ obtained from titration.

all of the hydronium ions could be released into the solution. This problem was evidenced by the low hydronium ion concentrations compared with the total sulfur content (p.e. for toluene the acid capacity should have been around $0.4 \mathrm{mmol} \mathrm{H}^{+} / \mathrm{g}$ instead of $0.05 \mathrm{mmol} \mathrm{H}^{+} / \mathrm{g}$ according to its final sulfur content of $0.77 \%$ ). Because ion exchange titrations are sensitive to the final wettability of the sample, the total sulfur content on the PS nanoparticles was used as the main indicator of the level of functionalization of these nanoparticles. Besides being a more robust method, elemental analysis can detect small differences in the number of functional groups that were attached.

The sulfur content $\left(\% \mathrm{~S}_{\text {total }}\right)$ of PS nanoparticles functionalized under different synthesis conditions varied from $0.26 \%$ to $18.59 \%$ (Table 2). Sulfur and carbon were not detected in $\mathrm{CoFe}_{2} \mathrm{O}_{4}$ or in silica-coated nanoparticles. Badley et al. reported \%S values from $3.25 \%$ to $8.32 \%$ for propyl-sulfonic acid-functionalized silicas [48]. Other works reported $1.17 \mathrm{mEq}$ S/g (3.7\%) for propyl-sulfonic modified SBA-15 [55] and 10.88\% S on thiolMCM-41 [56]. The \%S calculated from the ion exchange capacity values were lower than \%S obtained from the chemical analysis, which indicates that not all the incorporated sulfur $\left(\% \mathrm{~S}_{\text {total }}\right.$ was oxidized to the sulfonic acid form (\% $\left.{ }_{- \text {- озн }}\right)$. In this study, up to $63 \%$ of the total sulfur was oxidized to sulfonic acid, but for most samples was less than 20\%. Badley and Ford reported that only $34 \%$ of the sulfur incorporated was in the sulfonic acid form [48]. Cano-Serrano et al. reached 57\% for the best scenario [54]. The acid capacity of the nanoparticles could increase significantly if the mercapto-propyl groups were completely oxidized, but using stronger oxidizing conditions could detach the mercapto-propyl group [48] [54]. Some of the thiol groups could also have reacted with each other to form S-S bridges before the oxidation step was carried out [25] [57]. Moreover, some PS nanoparticles had a lot of thiol groups buried in lower molecular layers due to high loads of MPTMS and were not exposed to the oxidizing agent.

It has been calculated that $0.25 \%$ silane gives about eight molecular layers and $2 \%$ silane generates about 70 [58]. Low concentrations of MPTMS are preferred because the extent of the polymerization reaction is easier to control. 0.5\% MPTMS provided sufficient organosilane to reach about $5 \%-8 \% \mathrm{~S}$ on the PS nanoparticles when given enough time to react (Figure 3). Condensation of multiple layers of silane was expected when concentrations up to $4 \%$ or $5 \%$ of MPTMS were used. Deposition of multiple molecular layers could prevent oxidation of thiol groups in deeper layers. On the other hand, low silane concentrations could result in poor and uneven coverage of the surface with some areas of scarce functionalization.

The effect of water concentration on silanol deposition was studied using various blends of ethanol and water ( $0 \%$ - 50\% water in ethanol). Although several authors have recommended the use of only traces of water during the modification of surfaces with organosilanes, we found that the level of functionalization when using water concentrations under $20 \%$ was less than $1 \%$ (Figure 4). To obtain sulfur contents of about $5 \%-7 \%$, more than $33 \%$ water concentration had to be used in the synthesis setup.

All pure solvents yielded very low levels of acid functionalization (Table 2). Using non-polar solvents such as toluene is good to control silanol polymerization, but the hydrolysis and condensation reaction rates are too slow. We expect that longer reaction times would be needed to improve acid functionalization if non-polarsolvents are used. The moisture in the SiMNPs did not provide sufficient water to catalyze the reaction. Acetonitrile did not help the functionalization of the nanoparticles; the reaction media did not haze, which could be an indicator that MPTMS was not hydrolyzed. Methanol accelerated the reaction and helped the silanol groups react with each other before they attached to the surface. Some chunks of polysiloxane were observed, which 


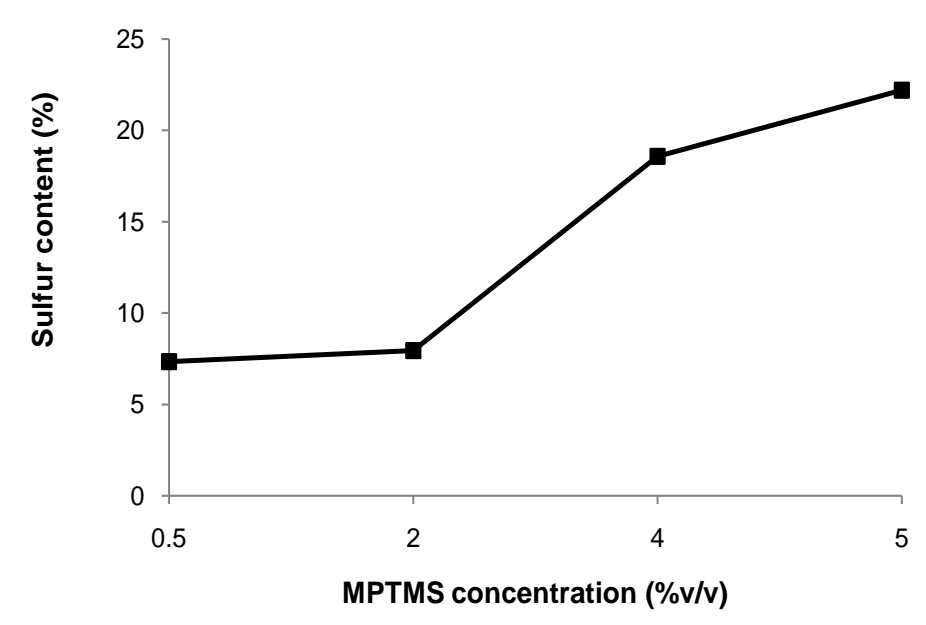

Figure 3. Effect of silane concentration on the total sulfur incorporated after functionalization of silica-coated nanoparticles. The grafting reactions were carried out in a 1:1 blend of ethanol and water for $16 \mathrm{~h}$.

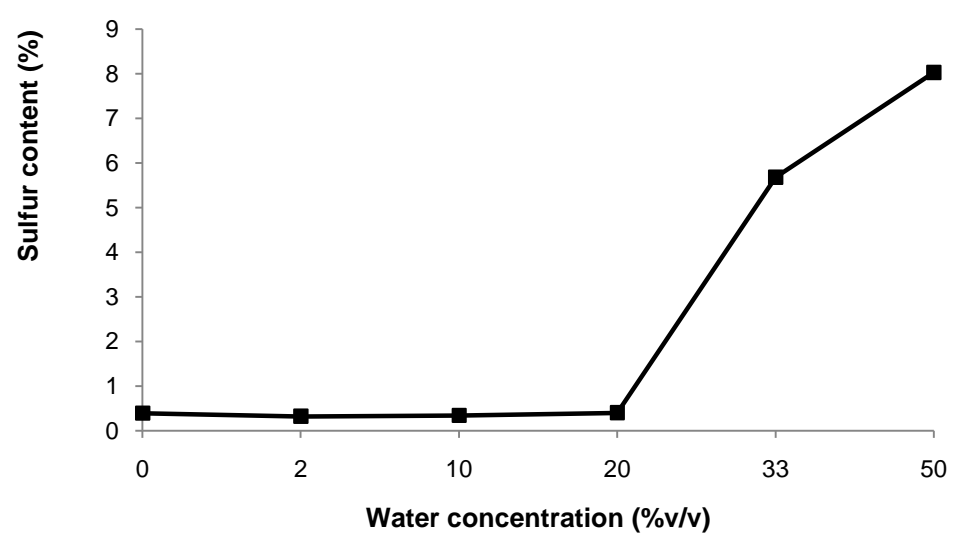

Figure 4. Effect of water concentration in the reaction media on the total sulfur incorporated after functionalization of silica-coated nanoparticles with $4 \%$ MPTMS. The grafting reactions were carried out in ethanol.

were separated from the nanoparticles using a 500-mesh sieve; the polysiloxane deposits were retained, and the nanoparticle dispersion passed through it. Ethanol alone could not catalyze the hydrolysis of MPTMS into propyl-silanols; at least 33\% water is needed to yield nanoparticles with a considerable number of functional groups. To some degree, ethanol controls the hydrolysis and condensation reactions since these reactions occurred when the reaction time was longer than $12 \mathrm{~h}$.

To obtain at least $6 \% \mathrm{~S}$ on the nanoparticles, at least $15 \mathrm{~h}$ of reaction time was needed when using $0.5 \%$ MPTMS and 50\% water (Figure 5). The level of functionalization increased with time of exposure of the nanoparticles to the silanol solution. Reducing reaction time may require higher concentrations of MPTMS in the solution, but then reaction 4 in Figure 1 could be favored.

FTIR spectra of the acid-functionalized nanoparticles with two different levels of functionalization are shown in Figure 6. More intense bands are seen in the nanoparticles with larger \%S. The peaks at $1620 \mathrm{~cm}^{-1}$ and 3400 $\mathrm{cm}^{-1}$ observed on the spectra have been attributed to the O-H vibration and stretching vibrations of physisorbed water [28] [59]. The weak peak at $3640 \mathrm{~cm}^{-1}$ corresponds to surface hydroxyl groups that are forming hydrogen bonds with other neighboring silanol groups [49] [59]; these silanol groups are not available for reaction with 


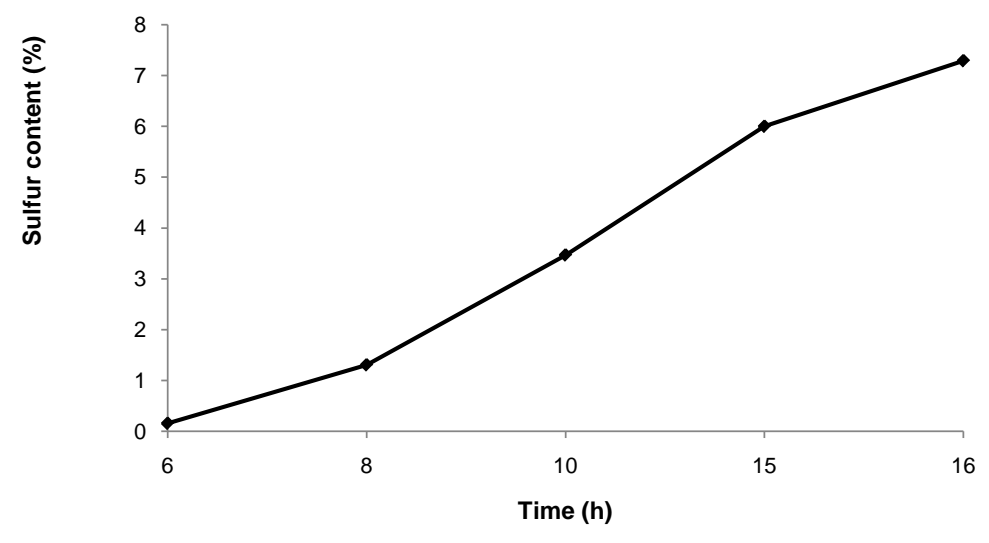

Figure 5. Effect of time on the total content of sulfur after functionalization with $0.5 \%$ MPTMS in a blend of ethanol and water (1:1).

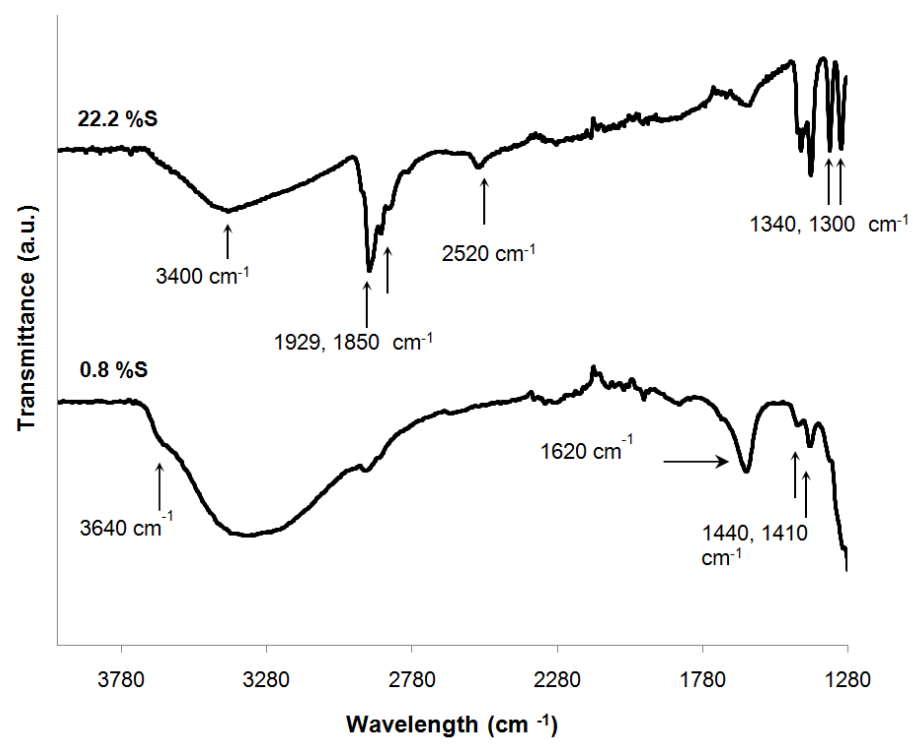

Figure 6. FT-IR spectra of PS nanoparticles with high and low levels of functionalization.

MPTMS. This could be advantageous because it maintains the hydrophilic properties of the silica surface. Wettability of the surface is preferred when the targeted reactions are carried out in aqueous solutions, because it is expected that MPMTS would cause an increase in the hydrophobicity of the surface [42] [54]. The peaks at 1850 $-1929 \mathrm{~cm}^{-1}$ are associated with symmetric and asymmetric vibrations of the C-H bonds in the propyl chain, respectively [37] [49] [60]. Deformation vibrations bands of $-\mathrm{CH}_{2}$ are also observed at $1440 \mathrm{~cm}^{-1}$ [47]. The peaks at $1410 \mathrm{~cm}^{-1}$ in both spectra have been assigned to the stretching vibrations of $\mathrm{S}=\mathrm{O}$ from undissociated acid sulfonic groups [61] [62]. The doublet at $1300-1340 \mathrm{~cm}^{-1}$ in the upper spectra has been attributed to stretching vibrations of $-\mathrm{SO}_{3}{ }^{-}$species [62]. The peak at $2520 \mathrm{~cm}^{-1}$ in the upper spectra can be associated with thiol groups from the mercaptopropyl groups that were not oxidized [54]. The peaks associated with the C-H bonds as well as the peaks corresponding the $\mathrm{O}=\mathrm{S}=\mathrm{O}$ and $-\mathrm{SO}_{3} \mathrm{H}$ bonds had larger intensities for PS nanoparticles that had larger \% S.

Before MPTMS modification, SiMNPs had an average particle size of $3.5 \pm 1.6 \mathrm{~nm}$ (Figure 7, image A,). After functionalization with MPTMS, the size of the nanoparticles increased with the incorporated \% S, indicating that the silanol has been deposited on their surface (Figure 7, image E). PS nanoparticles with a low level of functionalization $(0.77 \%$ S) had an average Feret size of $7.7 \pm 7.8 \mathrm{~nm}$ (Figure 7, image B). Surface modification carried out in toluene yielded small particles with low \% S. The condensation of MPTMS on the surface of the 

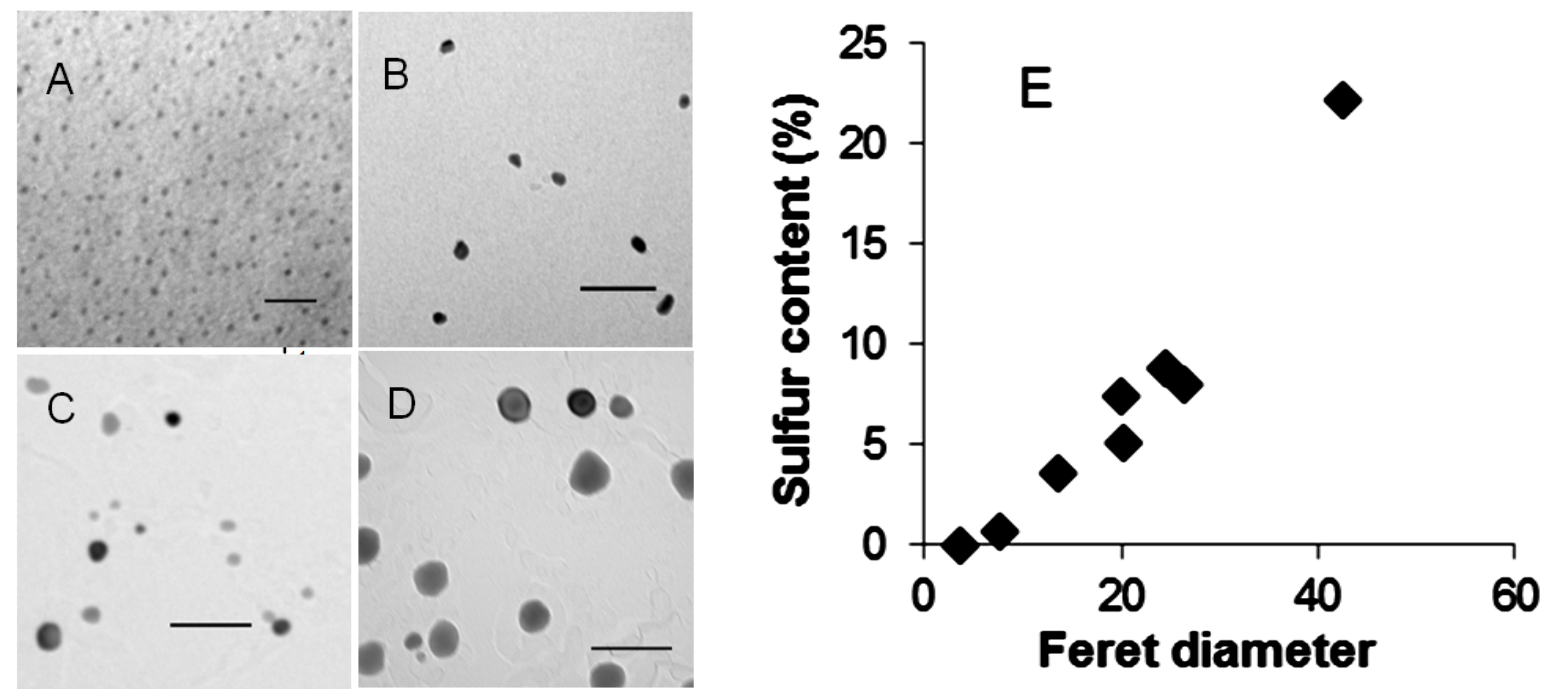

Figure 7. TEM images of propyl-sulfonic acid-functionalized nanoparticles. Image A depicts nanoparticles before MPTMS modification. Image B depicts PS nanoparticles with low sulfur content $(0.77 \%)$; image C depicts particles with a total sulfur content of $8.82 \%$, and image D depicts particles with $22.21 \% \mathrm{~S}$. The scale in all the images is $100 \mathrm{~nm}$ except for image A, which is $20 \mathrm{~nm}$. Image $\mathrm{E}$ depicts the relationship between incorporated sulfur vs. mean Feret diameter.

silica-coated nanoparticles was better controlled in anhydrous conditions even at high silane concentration (10\%). This can be explained by the fact that using nonpolar solvents such as toluene prevents excessive condensation of MPMTS [36] [42] [63]. PS nanoparticles with a medium level of functionalization (7.42\% S), which were synthesized in a 1:1 blend of water and ethanol with 2.5\% MPTMS are shown in Figure 7, image C. Their average size was $26.4 \pm 9.8 \mathrm{~nm}$. PS particles synthesized with 5\% MPTMS in a 1:1 blend of water and ethanol had the highest sulfur content $22.2 \%$ S obtained in this study. These particles also had the largest particle size. Their average size was $42.5 \pm 44.5 \mathrm{~nm}$ (Figure 7, image D). MPTMS is effectively hydrolyzed by water and reacts readily with $\mathrm{Si}-\mathrm{OH}$ groups that are available [42]. Therefore, it was expected to observe that high water and silane concentrations promoted the condensation of the hydrolyzate into a thick silica layer on the surface of the nanoparticles. Although, PS remained in the nanoscale at the high modification levels (e.g., 22.2\% S), excessive MPTMS condensation gives hydrophobic nanoparticles [64]. In aqueous conditions, hydrophobic nanoparticles agglomerate to reduce the surface area in contact with water molecules. The formation of nanoparticle aggregates in the reaction solution can hamper the catalytic activity of these nanoparticles by lowering the surface area available for reaction.

Results from the cellobiose hydrolysis using PS nanoparticles are shown in Figure 8. Increments in cellobiose conversion when the level of sulfur incorporated on the nanoparticles increased from $0.26 \%$ to $6.0 \% \mathrm{~S}$ can be observed. The conversion of cellobiose reached up to $96.0 \% \pm 0.7 \%$. The control experiment without nanoparticles gave a cellobiose conversion of $32.8 \% \pm 8.7 \%$. The hydrolysis of cellobiose was catalyzed with dispersions of PS nanoparticles that were equivalent to sulfuric acid solutions with concentrations less than $0.06 \%$ $(\mathrm{w} / \mathrm{w})$. Although the acid concentration provided by the nanoparticles was rather low, the results are promising and showed significant improvement in the conversion of cellobiose using acid-functionalized nanoparticles compared with the control. However, the catalyst lost about $30 \%-49 \%$ of the incorporated sulfur after the hydrolysis reaction. More research is required to find a post-grafting curing method to avoid leaching the acid functional groups.

\section{Conclusion}

Silane concentration, water content in the reaction media, and acid functionalization time had a significant effect on propyl sulfonic acid-functionalized nanoparticles. The most active nanoparticles with 5\% - 7\% S were synthesized with sufficient water (30\% - 50\%) and 0.5\% MPTMS with 15 - 16 h of reaction time. Propyl-sulfonic acid-functionalized nanoparticles effectively hydrolyzed cellobiose (96.0\%), which was significantly higher than the conversion of the control without catalyst (32.8\%). 


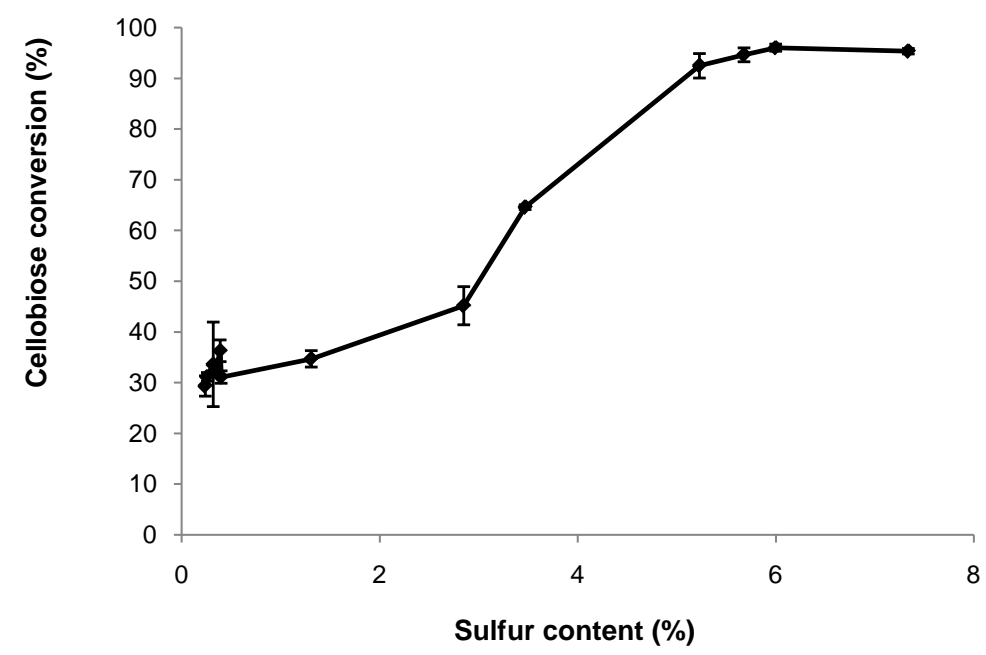

Figure 8. Glucose yield from the hydrolysis of cellobiose at $175^{\circ} \mathrm{C}$ for $30 \mathrm{~min}$. Before the reaction, reacting solutions were prepared with $1 \%(\mathrm{w} / \mathrm{w})$ catalyst and $4 \%(\mathrm{w} / \mathrm{v})$ cellobiose.

\section{Acknowledgements}

This research is funded by NSF award CNET1033538 and NSF EPSCoR Kansas Center for Solar Energy. This material is also based upon work supported by National Science Foundation Grant: From Crops to Commuting: Integrating the Social, Technological, and Agricultural Aspects of Renewable and Sustainable Biorefining (I-STAR); NSF Award No. DGE-0903701. This is contribution number 13-326-J from the Kansas Agricultural Experiment Station.

\section{References}

[1] Chang, M.M., Chou, T.Y.C. and Tsao, G.T. (1981) Structure, Pretreatment and Hydrolysis of Cellulose. In: Bioenergy, Springer, Berlin, Heidelberg, 15-42.

[2] Fleming, K., Gray, D. and Matthews, S. (2001) Cellulose Crystallites. Chemistry, 7, 1831-1835. http://dx.doi.org/10.1002/1521-3765(20010504)7:9<1831::AID-CHEM1831>3.0.CO;2-S

[3] Gardner, K.H. and Blackwell, J. (1974) Structure of Native Cellulose. Biopolymers, 13, 1975-2001. http://dx.doi.org/10.1002/bip.1974.360131005

[4] Okamura, K. (1991) Structure of Cellulose. In: Hon, D.N. and Shiraishi, N., Eds., Wood and Cellulosic Chemistry, Marcel Dekker, New York, 89-111.

[5] Bobleter, O. (1994) Hydrothermal Degradation of Polymers Derived from Plants. Progress in Polymer Science, 19, 797-841. http://dx.doi.org/10.1016/0079-6700(94)90033-7

[6] McMillan, J.D. (1994) Pretreatment of Lignocellulosic Biomass. In: Himmel, M.E., Baker, J.O. and Overend, R.P., Eds., Enzymatic Conversion of Biomass for Fuels Production, American Chemical Society, 292-294. http://dx.doi.org/10.1021/bk-1994-0566.ch015

[7] Wooley, R., Ruth, M., Glassner, D. and Sheehan, J. (1999) Process Design and Costing of Bioethanol Technology: A Tool for Determining the Status and Direction of Research and Development. Biotechnology Progress, 15, 794-803. http://dx.doi.org/10.1021/bp990107u

[8] Klein Marcuschamer, D., Oleskowicz Popiel, P., Simmons, B. and Blanch, H. (2012) The Challenge of Enzyme Cost in the Production of Lignocellulosic Biofuels. Biotechnology and Bioengineering, 109, 1083-1087. http://dx.doi.org/10.1002/bit.24370

[9] De Vries, R. and Visser, J. (2001) Aspergillus Enzymes Involved in Degradation of Plant Cell Wall Polysaccharides. Microbiology and Molecular Biology Reviews, 65, 497-522. http://dx.doi.org/10.1128/MMBR.65.4.497-522.2001

[10] Xiros, C., Katapodis, P. and Christakopoulos, P. (2011) Factors Affecting Cellulose and Hemicellulose Hydrolysis of Alkali Treated Brewers Spent Grain by Fusarium oxysporum Enzyme Extract. Bioresource Technology, 102, 16881696. http://dx.doi.org/10.1016/j.biortech.2010.09.108 
[11] Yadav, G.D. (2005) Synergism of Clay and Heteropoly Acids as Nano-Catalysts for the Development of Green Processes with Potential Industrial Applications. Catalysis Surveys from Asia, 9, 117-137.

[12] Chafin, S., Pennybaker, K., Fahey, D., Subramaniam, B. and Gong, K. (2008) Economic and Environmental Impact Analyses of Solid Acid Catalyzed Isoparaffin/Olefin Alkylation in Supercritical Carbon Dioxide. Industrial \& Engineering Chemistry Research, 47, 9072-9080. http://dx.doi.org/10.1021/ie800399s

[13] Harmer, M.A., Junk, C., Rostovtsev, V., Carcani, L.G., Vickery, J. and Schnepp, Z. (2007) Synthesis and Applications of Superacids. 1,1,2,2-Tetrafluoroethanesulfonic Acid, Supported on Silica. Green Chemistry, 9, 30-37. http://dx.doi.org/10.1039/b607428f

[14] Harmer, M.A., Farneth, W.E. and Sun, Q. (1998) Towards the Sulfuric Acid of Solids. Advanced Materials, 10, 12551255-1257. http://dx.doi.org/10.1002/(SICI)1521-4095(199810)10:15<1255::AID-ADMA1255>3.0.CO;2-T

[15] Dhepe, P. and Sahu, R. (2010) A Solid-Acid-Based Process for the Conversion of Hemicellulose. Green Chemistry, 12, 2153-2156. http://dx.doi.org/10.1039/c004128a

[16] Shimizu, K., Furukawa, H., Kobayashi, N., Itaya, Y. and Satsuma, A. (2009) Effects of Bronsted and Lewis Acidities on Activity and Selectivity of Heteropolyacid-Based Catalysts for Hydrolysis of Cellobiose and Cellulose. Green Chemistry, 11, 1627-1632. http://dx.doi.org/10.1039/b913737h

[17] Bootsma, J.A. and Shanks, B.H. (2007) Cellobiose Hydrolysis Using Organic-Inorganic Hybrid Mesoporous Silica Catalysts. Applied Catalysis A: General, 327, 44-51. http://dx.doi.org/10.1016/j.apcata.2007.03.039

[18] Vigier, K.D.O. and Jerome, F. (2010) Heterogeneously-Catalyzed Conversion of Carbohydrates. In: Rauter, A.P., Vogel, P. and Queneau, Y., Eds., Topics in Current Chemistry, Springer Berlin Heidelberg, Berlin, 63-92.

[19] Glass, N., Tjeung, R., Chan, P., Yeo, L. and Friend, J. (2011) Organosilane Deposition for Microfluidic Applications. Biomicrofluidics, 5, Article ID: 036501. http://dx.doi.org/10.1063/1.3625605

[20] Ulman, A. (1996) Formation and Structure of Self-Assembled Monolayers. Chemical Reviews, 96, 1533-1554. http://dx.doi.org/10.1021/cr9502357

[21] Norton, F.J. (1944) Organo-Silicon Films. General Electric Review, 47, 6-16.

[22] Hunter, M., Gordon, M., Barry, A., Hyde, J. and Heidenreich, R. (1947) Properties of Polyorganosiloxane Surfaces on Glass. Industrial \& Engineering Chemistry, 39, 1389-1395. http://dx.doi.org/10.1021/ie50455a605

[23] Corma, A. and Garcia, H. (2006) Silica-Bound Homogeneous Catalysts as Recoverable and Reusable Catalysts in Organic Synthesis. Advanced Synthesis \& Catalysis, 348, 1391-1412. http://dx.doi.org/10.1002/adsc.200606192

[24] Lai, D., Deng, L., Guo, Q. and Fu, Y. (2011) Hydrolysis of Biomass by Magnetic Solid Acid. Energy \& Environmental Science, 4, 3552-3557. http://dx.doi.org/10.1039/c1ee01526e

[25] Boveri, M., Agundez, J., Diaz, I., Perez Pariente, J. and Sastre, E. (2003) Synthesis and Characterisation of Ordered Mesoporous Acid Catalysts for Synthesis of Biodegradable Surfactants. Collection of Czechoslovak Chemical Communications, 68, 1914-1926. http://dx.doi.org/10.1135/cccc20031914

[26] Gao, Y. (2007) Nano-Reagents with Cooperative Catalysis and Their Uses in Multiple Phase Reactions. US Patent Publication No. US 20070184970 A1.

[27] Fan, J. and Gao, Y. (2006) Nanoparticle-Supported Catalysts and Catalytic Reactions: A Mini-Review. Journal of Experimental Nanoscience, 1, 457-475. http://dx.doi.org/10.1080/17458080601067708

[28] Phan, N.T.S. and Jones, C.W. (2006) Highly Accessible Catalytic Sites on Recyclable Organosilane-Functionalized Magnetic Nanoparticles: An Alternative to Functionalized Porous Silica Catalysts. Journal of Molecular Catalysis A: Chemical, 253, 123-131. http://dx.doi.org/10.1016/j.molcata.2006.03.019

[29] Raja, R. and Thomas, J.M. (2003) The Expanding World of Nanoparticle and Nanoporous Catalysts. In: The Chemistry of Nanostructured Materials, World Scientific Publishing Co. Pte. Ltd., Singapur, 329-357.

[30] Hayashi, K., Moriya, M., Sakamoto, W. and Yogo, T. (2009) Chemoselective Synthesis of Folic Acid-Functionalized Magnetite Nanoparticles via Click Chemistry for Magnetic Hyperthermia. Chemistry of Materials, 21, 1318-1325. http://dx.doi.org/10.1021/cm803113e

[31] Shylesh, S., Wagner, A., Seifert, A., Ernst, S. and Thiel, W. (2009) Cooperative Acid-Base Effects with Functionalized Mesoporous Silica Nanoparticles: Applications in Carbon-Carbon Bond-Formation Reactions. Chemistry: A European Journal, 15, 7052-7062. http://dx.doi.org/10.1002/chem.200900851

[32] Fiurasek, P. and Reven, L. (2007) Phosphonic and Sulfonic Acid-Functionalized Gold Nanoparticles: A Solid-State NMR Study. Langmuir, 23, 2857-2866. http://dx.doi.org/10.1021/la0629781

[33] Peña, L., Ikenberry, M., Hohn, K.L. and Wang, D. (2012) Acid-Functionalized Nanoparticles for Pretreatment of Wheat Straw. Journal of Biomaterials and Nanobiotechnology, 3, 342-352. http://dx.doi.org/10.4236/jbnb.2012.33032 
[34] Gill, C.S., Price, B.A. and Jones, C.W. (2007) Sulfonic Acid-Functionalized Silica-Coated Magnetic Nanoparticle Catalysts. Journal of Catalysis, 251, 145-152. http://dx.doi.org/10.1016/j.jcat.2007.07.007

[35] Siril, P.F., Davison, A.D., Randhawa, J.K. and Brown, D.R. (2007) Acid Strengths and Catalytic Activities of Sulfonic Acid on Polymeric and Silica Supports. Journal of Molecular Catalysis A: Chemical, 267, 72-78. http://dx.doi.org/10.1016/j.molcata.2006.11.022

[36] Tripp, C. and Hair, M. (1995) Reaction of Methylsilanols with Hydrated Silica Surfaces: The Hydrolysis of Trichloro-, Dichloro-, and Monochloromethylsilanes and the Effects of Curing. Langmuir, 11, 149-155. http://dx.doi.org/10.1021/la00001a027

[37] Dubois, L. and Zegarski, B. (1993) Bonding of Alkoxysilanes to Dehydroxylated Silica Surfaces: A New Adhesion Mechanism. Journal of Chemical Physics, 97, 1665-1670. http://dx.doi.org/10.1021/j100110a032

[38] Lee, L. (1968) Wettability and Conformation of Reactive Polysiloxanes. Journal of Colloid and Interface Science, 27, 751-760. http://dx.doi.org/10.1016/0021-9797(68)90109-4

[39] Plueddemann, E.P. (1982) Silane Coupling Agents. Plenum Press, New York. http://dx.doi.org/10.1007/978-1-4899-0342-6

[40] Mealey, S.K. and Thomas, B. (2005) Past, Present and Future of Organosilane Treatments for Fillers. Rubber World, 12, 32-34.

[41] Ishida, H. and Koenig, J. (1978) Fourier-Transform Infrared Spectroscopic Study of Silane Coupling Agent-Porous Silica Interface. Journal of Colloid and Interface Science, 64, 555-564. http://dx.doi.org/10.1016/0021-9797(78)90398-3

[42] Chirachanchai, S., Chungchamroenkit, R. and Ishida, H. (1999) Adsorption of Tetrasulfide-Functional Silane on High Surface Area Silica Treated with Aqueous and Non-Aqueous Solutions. Composite Interfaces, 6, 155-167. http://dx.doi.org/10.1163/156855499X00369

[43] Rondinone, A.J., Samia, A.C.S. and Zhang, Z.J. (1999) Superparamagnetic Relaxation and Magnetic Anisotropy Energy Distribution in $\mathrm{CoFe}_{2} \mathrm{O}_{4}$ Spinel Ferrite Nanocrystallites. Journal of Physical Chemistry B, 103, 6876-6880. http://dx.doi.org/10.1021/jp9912307

[44] Moumen, N., Bonville, P. and Pileni, M. (1996) Control of the Size of Cobalt Ferrite Magnetic Fluids: Mossbauer Spectroscopy. Journal of Chemical Physics, 100, 14410-14416. http://dx.doi.org/10.1021/jp953324w

[45] Shen, X., Fang, X., Zhou, Y. and Liang, H. (2004) Synthesis and Characterization of 3-Aminopropyltriethoxysilanemodified Superparamagnetic Magnetite Nanoparticles. Chemistry Letters, 33, 1468-1469. http://dx.doi.org/10.1246/cl.2004.1468

[46] Peña, L., Ikenberry, M., Ware, B., Hohn, K.L., Boyle, D. and Wang, D. (2011) Cellobiose Hydrolysis Using AcidFunctionalized Nanoparticles. Biotechnology and Bioprocess Engineering, 16, 1214-1222. http://dx.doi.org/10.1007/s12257-011-0166-8

[47] Rac, B., Molnar, A., Forgo, P., Mohai, M. and Bertoti, I. (2006) A Comparative Study of Solid Sulfonic Acid Catalysts Based on Various Ordered Mesoporous Silica Materials. Journal of Molecular Catalysis A: Chemical, 244, 46-57. http://dx.doi.org/10.1016/j.molcata.2005.08.043

[48] Badley, R. and Ford, W. (1989) Silica-Bound Sulfonic-Acid Catalysts. Journal of Organic Chemistry, 54, 5437-5443. http://dx.doi.org/10.1021/jo00284a014

[49] Brunel, D., Cauvel, A., Di Renzo, F., Fajula, F. and Fubini, B. (2000) Preferential Grafting of Alkoxysilane Coupling Agents on the Hydrophobic Portion of the Surface of Micelle-Templated Silica. New Journal of Chemistry, 24, 807813. http://dx.doi.org/10.1039/b002945i

[50] Melero, J.A., Stucky, G.D., van Grieken, R. and Morales, G. (2002) Direct Syntheses of Ordered SBA-15 Mesoporous Materials Containing Arenesulfonic Acid Groups. Journal of Materials Chemistry, 12, 1664-1670. http://dx.doi.org/10.1039/b110598c

[51] Kitano, M., Yamaguchi, D., Suganuma, S., Nakajima, K., Kato, H., Hayashi, S. and Hara, M. (2009) Adsorption-Enhanced Hydrolysis of Beta-1,4-Glucan on Graphene-Based Amorphous Carbon Bearing $\mathrm{SO}_{3} \mathrm{H}, \mathrm{COOH}$, and $\mathrm{OH}$ Groups. Langmuir, 25, 5068-5075. http://dx.doi.org/10.1021/la8040506

[52] Zeng, M., Ximenes, E., Ladisch, M., Mosier, N., Vermerris, W., Huang, C. and Sherman, D. (2012) Tissue-Specific Biomass Recalcitrance in Corn Stover Pretreated with Liquid Hot-Water: Enzymatic Hydrolysis (Part 1). Biotechnology and Bioengineering, 109, 390-397. http://dx.doi.org/10.1002/bit.23337

[53] Sluiter, A., Hames, B., Ruiz, R., Scarlata, C., Sluiter, J. and Templeton, D. (2008) Determination of Sugars, Byproducts and Degradation Products in Liquid Fraction Process Samples. NREL/TP-510-42623.

[54] Cano Serrano, E., Campos Martin, J. and Fierro, J. (2003) Sulfonic Acid-Functionalized Silica through Quantitative Oxidation of Thiol Groups. Chemical Communications, 2, 246-247. http://dx.doi.org/10.1039/b210766j

[55] Melero, J., Fernando Bautista, L., Morales, G., Iglesias, J. and Sanchez Vazquez, R. (2010) Biodiesel Production from 
Crude Palm Oil Using Sulfonic Acid-Modified Mesostructured Catalysts. Chemical Engineering Journal, 161, 323331. http://dx.doi.org/10.1016/j.cej.2009.12.037

[56] Lim, M., Blanford, C. and Stein, A. (1998) Synthesis of Ordered Microporous Silicates with Organosulfur Surface Groups and Their Applications as Solid Acid Catalysts. Chemistry of Materials, 10, 467-470. http://dx.doi.org/10.1021/cm970713p

[57] Diaz, I., Marquez-Alvarez, C., Mohino, F., Perez-Pariente, J. and Sastre, E. (2000) Combined Alkyl and Sulfonic Acid Functionalization of MCM-41-Type Silica: Part 1. Synthesis and Characterization. Journal of Catalysis, 193, 283-294. http://dx.doi.org/10.1006/jcat.2000.2898

[58] Sterman, S. and Bradley, H. (1961) A New Interpretation of the Glass-Coupling Agent Surface through Use of Electron Microscopy. Polymer Engineering \& Science, 1, 224-233.

[59] Hair, M. (1975) Hydroxyl-Groups on Silica Surface. Journal of Non-Crystalline Solids, 19, 299-309. http://dx.doi.org/10.1016/0022-3093(75)90095-2

[60] Colilla, M., Izquierdo-Barba, I., Sanchez-Salcedo, S., Fierro, J., Hueso, J. and Vallet-Regi, M. (2010) Synthesis and Characterization of Zwitterionic SBA-15 Nanostructured Materials. Chemistry of Materials, 22, 6459-6466. http://dx.doi.org/10.1021/cm102827y

[61] Alvaro, M., Corma, A., Das, D., Fornes, V. and Garcia, H. (2005) “Nafion”-Functionalized Mesoporous MCM-41 Silica Shows High Activity and Selectivity for Carboxylic Acid Esterification and Friedel-Crafts Acylation Reactions. Journal of Catalysis, 231, 48-55. http://dx.doi.org/10.1016/j.jcat.2005.01.007

[62] Buzzoni, R., Bordiga, S., Ricchiardi, G., Spoto, G. and Zecchina, A. (1995) Interaction of $\mathrm{H}_{2} \mathrm{O}, \mathrm{CH}_{3} \mathrm{OH},\left(\mathrm{CH}_{3}\right)_{2} \mathrm{O}$, $\mathrm{CH}_{3} \mathrm{CN}$ and Pyridine with the Superacid Perfluorosulfonic Membrane Nafion: An IR and Raman Study. Journal of Chemical Physics, 99, 11937-11951. http://dx.doi.org/10.1021/j100031a023

[63] Bossaert, W., De Vos, D., Van Rhijn, W., Bullen, J. and Grobet, P. (1999) Mesoporous Sulfonic Acids as Selective Heterogeneous Catalysts for the Synthesis of Monoglycerides. Journal of Catalysis, 182, 156-164. http://dx.doi.org/10.1006/jcat.1998.2353

[64] Macquarrie, D., Jackson, D., Mdoe, J. and Clark, J. (1999) Organomodified Hexagonal Mesoporous Silicates. New Journal of Chemistry, 23, 539-544. http://dx.doi.org/10.1039/a900839j 
Scientific Research Publishing (SCIRP) is one of the largest Open Access journal publishers. It is currently publishing more than 200 open access, online, peer-reviewed journals covering a wide range of academic disciplines. SCIRP serves the worldwide academic communities and contributes to the progress and application of science with its publication.

Other selected journals from SCIRP are listed as below. Submit your manuscript to us via either submit@scirp.org or Online Submission Portal.
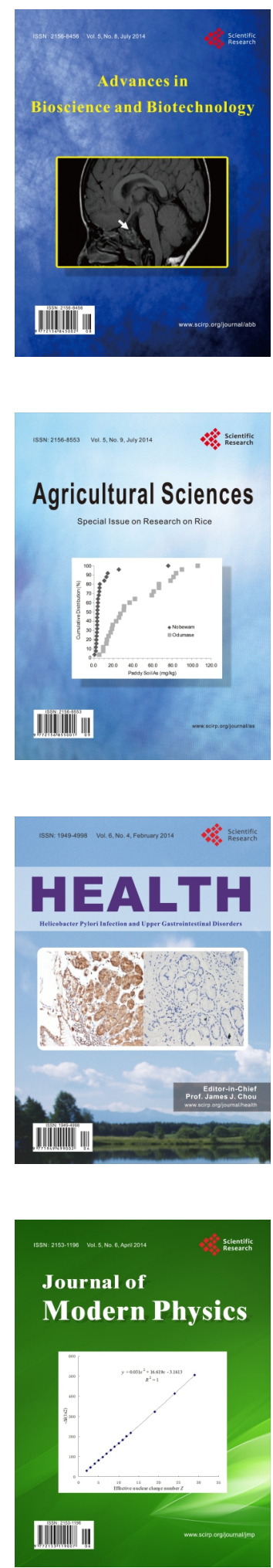
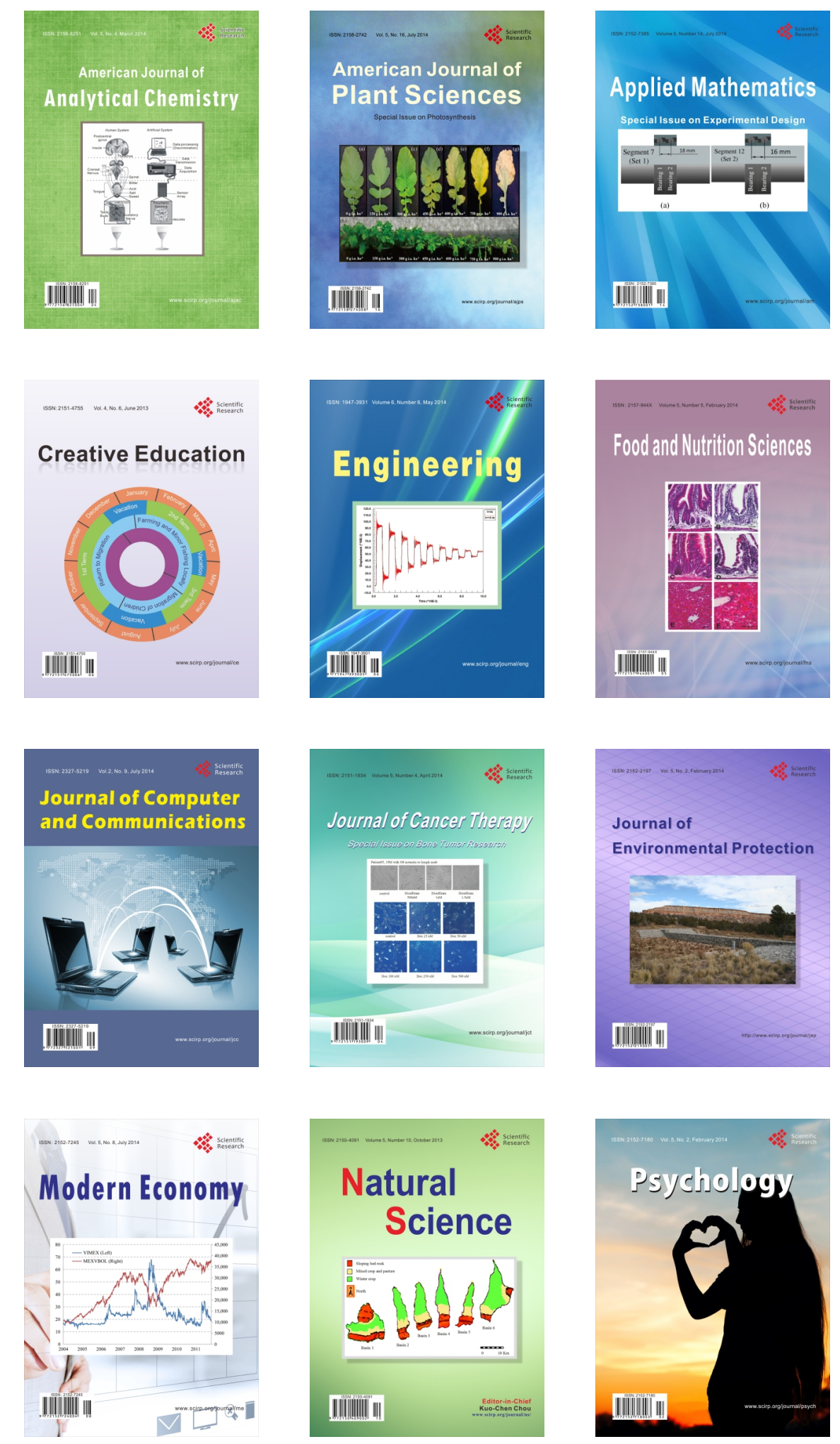